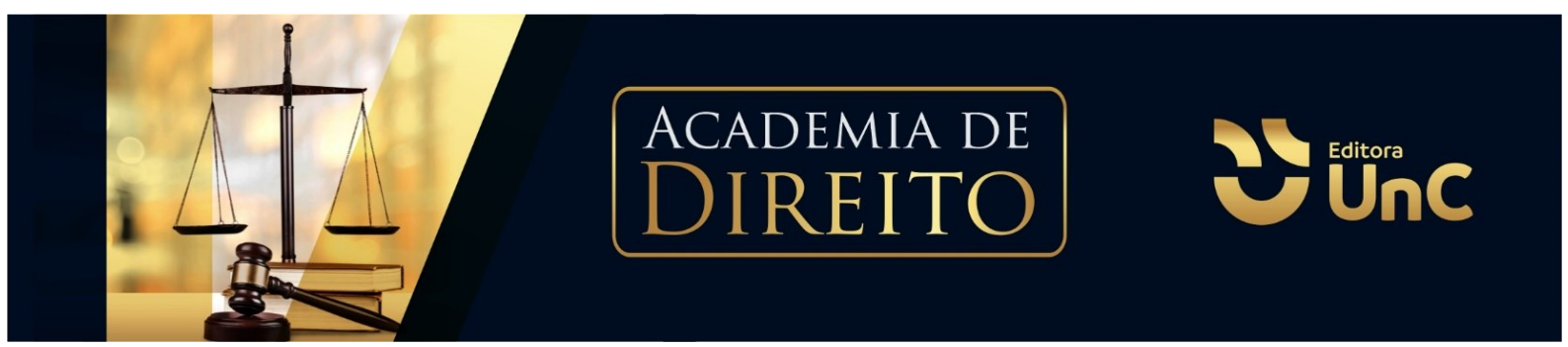

\title{
OS OBSTÁCULOS PARA MANUTENÇÃO DA RESCISÃO DO CONTRATO INDIVIDUAL DE TRABALHO POR JUSTA CAUSA
}

\section{THE OBSTACLES FOR MAINTAINING THE TERMINATION OF THE INDIVIDUAL LABOR CONTRACT FOR FAIR CAUSE}

Juliani Pontes Gonçalves ${ }^{1}$ Juliana Maciel ${ }^{2}$

\begin{abstract}
RESUMO
A justa causa é uma das modalidades de rescisão, do contrato individual de trabalho, aplicadas nos casos em que houver uma infração contratual, praticada pelo empregado, seja ela por ação ou omissão, revestida de gravidade e que torne insustentável a relação de trabalho. As hipóteses para o cabimento desta modalidade de rescisão contratual têm previsão legal na CLT, por meio de rol taxativo, nos moldes do artigo 482 da CLT. Tendo em vista que a lei traz um rol taxativo, porém de ampla interpretação, abrindo margem para subjetividade na análise judiciária, pesquisa-se sobre as dificuldades para manutenção da rescisão por justa causa, quando o caso concreto chega à análise do Poder Judiciário. $O$ presente artigo tem por objetivo principal auxiliar empresários, acadêmicos e profissionais da área do direito do trabalho, a obterem uma melhor compreensão acerca das decisões jurídicas do Tribunal Regional do Trabalho da $12^{\mathrm{a}}$ Região, sobre as rescisões dos contratos de trabalho com justa causa. Quanto a metodologia utilizada nesta pesquisa, é a descritiva, com ênfase no estudo bibliográfico e jurisprudencial. Faz-se um breve apanhado do contexto histórico, seguido pelas questões pertinentes ao contrato individual de trabalho. Podemos concluir que a empresa deve estar segura que estejam presentes todos os requisitos antes de aplicar a justa causa, para não correr o risco de ensejar na reversão da justa causa, conforme examinado nos julgados.
\end{abstract}

Palavras-Chave: Dispensa motivada. Empregado. Empregador.

\footnotetext{
${ }^{1}$ Graduanda em Direito da Universidade do Contestado. Santa Catarina. Brasil. E-mail: julianipontes@hotmail.com

${ }^{2}$ Mestranda em Desenvolvimento Regional. Universidade do Contestado. Docente do curso de direito da Universidade do Contestado. Santa Catarina. Brasil. E-mail: juliianamaciel@hotmail.com
} 


\begin{abstract}
The just cause is one of the modalities of termination, of the individual employment contract, applied in cases where there is a contractual infraction, practiced by the employee, whether by action or omission, with gravity and which makes the employment relationship unsustainable. The assumptions for the suitability of this type of contractual termination are legally provided for in the CLT, by means of a tax list, in accordance with Article 482 of the CLT. Bearing in mind that the law has a definitive role, but with a wide interpretation, opening the possibility for subjectivity in the judicial analysis, research on the difficulties to maintain termination for just cause, when the specific case comes to the analysis of the Judiciary. The main objective of this article is to assist businessmen, academics and professionals in the field of labor law, to obtain a better understanding of the legal decisions of the Regional Labor Court of the 12th Region, regarding terminations of employment contracts with just cause. As for the methodology used in this research, it is descriptive, with an emphasis on bibliographic and jurisprudential study. A brief overview of the historical context is made, followed by questions related to the individual employment contract. We can conclude that the company must be sure that all requirements are present before applying the just cause, so as not to run the risk of giving rise to the reversal of the just cause, as examined in the judgments.
\end{abstract}

Keywords: Dispensation motivated. Employee. Employer.

\title{
1 INTRODUÇÃO
}

Uma das causas de ruptura do pacto laboral é a justa causa, é uma dispensa do empregado decorrente de um ato, que se sustenta com gravidade e praticado pelo empregado o que torna o vínculo entre empregado e empregador insustentável. No entanto para que esse funcionário seja demitido por justa causa, ele deve necessariamente se enquadrar nas hipóteses que levam ao empregador justificar seu ato, sustentado pelo artigo 482 da CLT.

Apesar de que no Brasil seja adotado o sistema taxativo, por meio de previsão legal, enumerando as hipóteses de incidência da rescisão do contrato por justa causa, tem-se margem para interpretações diversas quando se está diante do caso concreto, ensejando subjetividade na análise pelo Poder Judiciário. Consequentemente dificultando a manutenção da justa causa nos casos de demissão que chegam à apreciação judiciária.

Pelo fato de a justa causa ser a penalidade máxima aplicada ao trabalhador, deve haver uma cautela na sua aplicação. De modo que, se a punição for considerada abusiva ou excessiva, ela pode ser questionada pelo empregado em juízo e o Poder 
Judiciário irá decidir a respeito da regularidade e caberá a ele decretar nulidade ou não da pena aplicada.

Portanto, o presente estudo tem a finalidade de analisar os obstáculos enfrentados pelo empregador na manutenção da rescisão do contrato individual de trabalho por justa causa.

Para uma melhor compreensão, será abordado inicialmente o aspecto histórico do Direito do Trabalho e as proteções advindas com esta evolução, seguido do conceito do contrato individual de trabalho, por se tratar do vínculo da relação de emprego. Bem como, serão analisados os aspectos da rescisão por justa causa e os obstáculos para sua manutenção, com uma análise dos julgados pertinentes.

Tem por objetivo principal, auxiliar empresários, acadêmicos e profissionais da área a uma melhor compreensão dos pareceres jurídicos locais acerca do tema. Uma vez que é baseada em diferentes formas de interpretações doutrinárias, sem um parâmetro geral específico.

Analisando as exigências para aplicação da justa causa, visto que, se não empregada de forma correta, a justa causa poderá ser revertida posteriormente na justiça do trabalho. Fato esse que gera insegurança para os empregadores, pois nos casos em que é revertida, acarretará um custo excessivo para a empresa, que além de ser condenada a pagar as verbas rescisórias, ainda precisará arcar com despesas processuais, multas compensatórias e até mesmo indenização por danos morais.

\section{CONTRATO INDIVIDUAL DE TRABALHO}

A evolução do direito do trabalho surgiu com a necessidade de regulamentar as relações de trabalho. Visto que, nos tempos passados os trabalhadores não eram considerados sujeitos de direitos e não possuíam quaisquer direitos ou proteções em relação ao trabalho.

O escravo era destituído do direito à vida, não possuía qualquer dignidade, nas palavras de Alice de Barros (2011, p.45):

[..] o escravo enquadrava-se como objeto do direito de propriedade, não como sujeito de direito, razão pela qual se torna inviável falar-se de um Direito do Trabalho enquanto predominava o trabalho escravo. É que o contrato de trabalho, núcleo de nossa disciplina, pressupõe a existência de dois sujeitos 
de direito: empregado e empregador. Ausente um deles, a relação jurídica está fora de tutela".

Após esse período, durante o Feudalismo havia o regime da servidão, onde "os senhores feudais davam proteção militar e política aos servos, que não eram livres, mas, ao contrário, tinham de prestar serviços na terra do senhor feudal" (MARTINS, 2019, p. 31).

O surgimento do direito do trabalho vem com a Revolução Industrial, iniciada no século XVIII, onde houve a substituição do trabalho manual, força humana, pelas máquinas. Somente após a destruição das relações servis que inicia a relação empregatícia, nas palavras de Delgado (2017, p.92):

\begin{abstract}
De fato, apenas já no período da Revolução Industrial é que esse trabalhador seria reconectado, de modo permanente, ao sistema produtivo, através de uma relação de produção inovadora, hábil a combinar liberdade (ou melhor, separação em face dos meios de produção e seu titular) e subordinação. Trabalhador separado dos meios de produção (portanto juridicamente livre), mas subordinado no âmbito da relação empregatícia ao proprietário (ou possuidor, a qualquer título) desses mesmos meios produtivos - eis a nova equação jurídica do sistema produtivo dos últimos dois séculos.
\end{abstract}

Ocorre que, mesmo existindo uma relação empregatícia, não havia quaisquer proteções ao trabalhador, que se sujeitavam a condições degradantes. Os trabalhadores se uniram e reivindicaram em busca de melhorias, nesse momento o Estado precisou intervir nas relações de trabalho, com intuito de proteger o trabalhador. Impôs limitações a liberdade das partes, proibindo os abusos de poder por parte do empregador, em relação àqueles que não detinham poder econômico (GARCIA, 2017).

A história do Direito do Trabalho foi marcada pelas conquistas obtidas ao longo dos anos, garantindo condições mínimas de vida aos trabalhadores, protegendo os direitos da pessoa humana e evitando abusos em relação àqueles que não detêm poder econômico. Sendo de suma importância esse contexto histórico para as relações de trabalho contemporânea.

Atualmente o contrato individual de trabalho é o que rege a relação entre empregado e empregador, sendo ele o acordo de vontades entre as partes, que irá regular a relação de emprego. Conforme conceitual Martins (2019, p.77): 
Contrato de trabalho é o negócio jurídico entre empregado e empregador sobre as condições de trabalho.

O contrato de trabalho é, por conseguinte, um pacto de atividade, pois não se contrata um resultado. Deve haver continuidade na prestação de serviços, que deverão ser remunerados e dirigidos por aquele que obtém a referida prestação. Nota-se a existência de um acordo de vontades, caracterizando a autonomia privada das partes.

O vínculo da relação de emprego é atribuído pelo contrato de trabalho, negócio jurídico bilateral, celebrado entre empregado e empregador, o qual pode ser firmado de forma tácita, escrita ou verbal. Conforme sua previsão no artigo 442 da CLT, "Contrato individual de trabalho é o acordo tácito ou expresso, correspondente a relação de emprego" (BRASIL, 1943).

No instrumento irá conter as obrigações dos sujeitos, de acordo com a vontade das partes e as obrigações impostas por lei. Através dele, o trabalhador se compromete a prestar o serviço, de forma pessoal, intransferível, continuada e subordinada, em conseguinte o empregador irá fazer o pagamento referente aos serviços prestados.

A relação de emprego deverá ser regida de acordo com os termos estabelecidos no contrato, respeitando os aspectos legais. Explana Cassar (2017, p. 239) sobre o assunto:

Como é sabido, estas regras impostas pela lei são de ordem pública, cogentes e imperativas. Logo, as partes não podem delas dispor. Tal fato limita sobremaneira a autonomia de vontade dos contratantes, reduzindo a capacidade de ajustar. São verdadeiros contratos regulamentados, como chamava Savatier. Este excesso de contratos, como o de seguro, transporte, locação, consumidor etc., logo, não é um fenômeno peculiar do Direito do Trabalho.

O ajuste contratual pode ocorrer de duas formas, na expressa, onde as partes estipulam o conteúdo básico de seus direitos e obrigações recíprocas, que podem ser feitas de forma escrita ou verbal. Outra possibilidade é a forma tácita, onde compreendemos o contrato em um conjunto de atos coordenados das partes, portanto, uma vez presente todos os requisitos, mesmo que não haja um contrato expresso, será caracterizada uma relação de emprego (GODINHO, 2017)

Em relação ao tempo de duração, em regra, é por tempo indeterminado, onde não há um prazo para extinguir o contrato, ficando a critério das partes encerrarem a qualquer momento (MARTINEZ, 2016). 
Outra possibilidade é o contrato por tempo determinado, o qual possui um prazo definido para extinção, "o contrato de trabalho cuja vigência dependa de termo prefixado ou da execução de serviços especificados ou ainda da realização de certo acontecimento suscetível de previsão aproximada" (BRASIL, 1943).

Proveniente da reforma trabalhista de 2017, temos a opção do trabalho intermitente, modalidade em que o trabalhador possui carteira assinada, mas trabalha somente quando é convocado. A prestação de serviço ocorre de forma não contínua, alternando períodos de prestação de serviço e de inatividade.

O contrato intermitente deve ser celebrado por escrito e deve conter especificamente o valor da hora de trabalho, que não pode ser inferior ao valor horário do salário mínimo ou àquele devido aos demais empregados do estabelecimento que exerçam a mesma função em contrato intermitente ou não (BRASIL, 1943, art. 452-A).

Quanto aos sujeitos do contrato, temos o contrato individual ou o contrato plúrimo, sendo o primeiro firmado entre um trabalhador e um tomador de serviços. Já o contrato plúrimo, ou por equipe, é caracterizada quando o tomador de serviços contrata um determinado número de trabalhadores que já estão unidos pelo seu trabalho, ou seja, o empregador contrata uma equipe.

\section{ASPECTOS DA RESCISÃO POR JUSTA CAUSA}

Quando houver uma infração contratual, praticada pelo empregado, seja por ação ou omissão, podemos estar diante de uma justa causa. Sendo esta a ruptura do contrato individual de trabalho por um motivo provocado pela parte, devendo estar revestida de algumas características para que seja reconhecida (NASCIMENTO, 2014).

Existe uma divergência doutrinaria acerca dos conceitos de rescisão por justa causa e de falta grave, não sendo precisa nem mesmo a CLT acerca do uso dos termos. Contudo, podemos entender que a falta grave é considerada um ato mais grave e diz respeito a falta grave praticada pelo empregado estável. Já a expressão "justa causa" é utilizada para se referir a resolução contratual decorrente de ato revestido de gravidade, praticado pelo empregado (MARTINS, 2020). 
O ato faltoso, revestido de gravidade, que irá configurar a justa causa, é caracterizado pelo descumprimento das obrigações pactuadas no contrato de trabalho. Visto que o vínculo que une empregado e empregador é o contrato de trabalho, o qual prevê obrigações mútuas às partes, que devem ser respeitadas.

Gustavo Garcia (2017, p. 384) conceitua justa causa como:

A prática de ato que configure séria violação dos deveres do empregado, rompendo a confiança inerente à relação de emprego, tornando indesejável ou inviável a manutenção do referido vínculo. A dispensa por justa causa, por sua vez, pode ser conceituada como a cessação do contrato de trabalho em razão da prática de ato faltoso, dotado de gravidade, abalando a fidúcia entre as partes da relação de emprego.

O poder empregatício que confere poderes ao empregador para que as sanções sejam aplicadas, ele pode ser definido como um conjunto de prerrogativas, asseguradas pelo ordenamento jurídico, conferidas ao empregador, com a finalidade de que o mesmo consiga alcançar seus interesses e finalidades (GODINHO, 2017).

Sendo o empregado um trabalhador subordinado, está sujeito ao poder de direção do empregador, que irá definir como devem ser desenvolvidas as atividades do contrato de trabalho.

Explana Sérgio Pinto Martins (2020, p. 357):

\begin{abstract}
Representa o poder de direção do empregador uma forma de limitação à autonomia da vontade do empregado, que fica sujeito às determinações do empregador.

O poder de direção do empregador é unilateral, mas não é um direito absoluto. Só por ser um direito, tem limites. O direito de uma pessoa termina onde começa o direito de outra pessoa. Limites externos: Constituição, leis, norma coletiva, contrato. Limites internos: boa-fé objetiva e exercício regular do direito. Se for irregular, o negócio jurídico é ilícito (art. 188, I, do Código Civil).

Compreende o poder de direção não só o de organizar suas atividades, como também o de controlar e disciplinar o trabalho, de acordo com os fins do empreendimento.
\end{abstract}

O poder de organização permite ao empregador que sejam expedidos comandos para orientar seus funcionários da forma com que o serviço deve ser realizado. Já o poder de controle permite ao empregador fiscalizar a execução dos serviços de seus empregados.

Para Luiz José de Mesquita (1991, apud, MARTINEZ, 2016, p.317), o poder diretivo "encontra fundamento no interesse social da empresa, que exige uma perfeita 
organização profissional do trabalho, fornecido por seus subordinados a fim de se atingir um bem comum de ordem econômico-social".

O poder disciplinar permite que sejam aplicadas sanções quando o empregado cometer algum tipo de infração relacionado a atividade desempenhada. As medidas sancionatórias que podem ser aplicadas são: a advertência, seja ela na forma escrita ou verbal; a suspensão, desde que em conformidade com a CLT; e a justa causa, sendo a punição mais grave do contrato de trabalho.

Sergio Pinto Martins (2019, p. 114) aduz sobre o assunto:

O poder disciplinar é um complemento do poder de direção, do poder de o empregador determinar ordens na empresa, que, se não cumpridas, podem gerar penalidades ao empregado, que deve se ater à disciplina e respeito ao seu patrão, por estar sujeito a ordens de serviço, que devem ser cumpridas, salvo se ilegais ou imorais. Logo, o empregado pode estabelecer penalidades aos seus empregados.

Para que seja possível a aplicação da justa causa é necessária que o ato praticado pelo empregado esteja de acordo com as hipóteses previstas em lei. $\mathrm{O}$ artigo 482 da CLT (BRASIL, 1943) arrola as faltas genéricas, que se aplicam para todos os empregados submetidos ao sistema celetista:

Art. 482 - Constituem justa causa para rescisão do contrato de trabalho pelo empregador:

a) ato de improbidade;

b) incontinência de conduta ou mau procedimento;

c) negociação habitual por conta própria ou alheia sem permissão do empregador, e quando constituir ato de concorrência à empresa para a qual trabalha o empregado, ou for prejudicial ao serviço;

d) condenação criminal do empregado, passada em julgado, caso não tenha havido suspensão da execução da pena;

e) desídia no desempenho das respectivas funções;

f) embriaguez habitual ou em serviço;

g) violação de segredo da empresa;

h) ato de indisciplina ou de insubordinação;

i) abandono de emprego;

j) ato lesivo da honra ou da boa fama praticado no serviço contra qualquer pessoa, ou ofensas físicas, nas mesmas condições, salvo em caso de legítima defesa, própria ou de outrem;

k) ato lesivo da honra ou da boa fama ou ofensas físicas praticadas contra o empregador e superiores hierárquicos, salvo em caso de legítima defesa, própria ou de outrem;

I) prática constante de jogos de azar.

$\mathrm{m}$ ) perda da habilitação ou dos requisitos estabelecidos em lei para o exercício da profissão, em decorrência de conduta dolosa do empregado. 
Ímproba é uma pessoa que não é honesta, desta forma a CLT usa a expressão ato de improbidade para configurar a justa causa pelos atos desonestos praticados pelo empregado. Entretanto nem todo ato desonesto é configurado como improbidade, visto que a CLT elenca alguns atos que são desonestos, mas que tem uma previsão específica (GIGLIO, 2000).

As hipóteses previstas na alínea $b$ são duas situações distintas, a incontinência diz respeito a um comportamento irregular ligado a moral sexual. Já o mau procedimento trata-se do comportamento irregular do empregado, que atinja a moral de forma geral (GARCIA, 2017).

Para Godinho (2017, p. 1369) a incontinência de conduta "está vinculada à conduta sexual imoderada, desregrada, destemperada ou, até mesmo, inadequada, desde que afete o contrato de trabalho ou ambiente laborativo". Já o mau procedimento "trata-se de conduta culposa do empregado que atinja a moral, sob o ponto de vista geral, excluído o sexual".

Negociação habitual por conta própria ou alheia, sem permissão do empregador e quando constituir ato de concorrência à empresa para a qual trabalha o empregado, ou for prejudicial ao serviço. A negociação é a prática da atividade desempenhada pelo empregado durante o contrato de trabalho, que seja prejudicial ao serviço ou que implique concorrência com o empregador, devendo ocorrer de forma habitual para ser caracterizada (GARCIA, 2017).

São abrangidos dois tipos jurídicos, sendo o primeiro correspondente à concorrência desleal do empregado a seu patrão, como exemplo temos o técnico em manutenção de aparelhagem da clientela empresarial que pactua, à parte com os respectivos clientes e por um preço mais módico, a prestação pessoal do mesmo serviço, que deveria ser prestado em nome da empresa. O segundo tipo jurídico é a negociação habitual sem a permissão do empregador, como exemplo temos o funcionário que faz vendas informais no ambiente laborativo (DELGADO, 2017).

Condenação criminal do empregado, passada em julgado, caso não tenha havido suspensão da execução da pena. Elucida sobre o assunto Barbosa Garcia (2017, p. 390) "se o empregado for condenado, criminalmente, por sentença transitada em julgado, caso não haja suspensão condicional da pena, o empregador pode dispensá-lo por justa causa". 
No decorrer do processo há uma presunção de inocência do acusado, desta forma, quando houver a prisão preventiva do empregado será suspenso o contrato de trabalho. Se o mesmo for absolvido poderá dar continuidade ao vínculo laboral, não estando o empregador autorizado a despedi-lo com justa causa (MARTINEZ, 2016).

Desídia no desempenho das respectivas funções, entende-se pelo desinteresse do empregado no tocante à prestação de serviço, quando executa suas obrigações com má vontade. Para que seja configurada como justa causa, em regra, caracteriza-se pela reiteração de atos faltosos de menor gravidade.

Bomfim (2018, p. 1071) traz a definição da palavra desídia juntamente com uma explicação sobre o assunto:

\begin{abstract}
A palavra desídia significa 'disposição para evitar qualquer esforço físico ou mental, [...] indolência, ociosidade, preguiça, de zelo, desleixo, incúria, negligência', falta de cuidado, desmazelo, falta de atenção, desinteresse, indiferença. Assim, o empregado relapso, imprudente, negligente, desinteressado, imperito, que não exerce suas atividades com exação, que tem má vontade, pode ser despedido por justa causa, com base no art. 482, e, da CLT- desídia.
\end{abstract}

Embriaguez habitual ou em serviço abrange dois tipos jurídicos semelhantes, onde ambos se referem ao estado de embriaguez, proveniente do uso de álcool ou drogas. Poderá configurar pela habitualidade, quando o empregado fica embriagado frequentemente, ainda que não esteja de serviço, mas que repercute no ambiente de trabalho. A embriaguez em serviço ocorre quando o empregado se encontra embriagado durante a prestação de serviço, podendo ser caracterizada por apenas uma falta, sem a necessidade da repetição (LEITE, 2017).

Violação de segredo da empresa, compreende o tipo jurídico quando o empregado divulga algum segredo, pertencente a empresa, que não deveria se tornar público e causa prejuízos a mesma. Conforme menciona Cassar (2018, p. 1076) "é dever do empregado manter segredo acerca dos detalhes que cercam a atividade do empregador. Este dever decorre também de sua discrição".

Ato de indisciplina ou de insubordinação, nesta alínea também são arrolados dois tipos jurídicos, sendo o da indisciplina o descumprimento das regras gerais da empresa. Já a insubordinação, diz respeito ao descumprimento de ordens específicas dadas pelos superiores ao empregado (BARROS, 2011). 
Irá configurar o abandono de emprego a ausência injustificada do empregado ao trabalho, no decurso do prazo de trinta dias consecutivos, conforme fixado pela jurisprudência, sem qualquer manifestação por parte do empregado (CASSAR, 2018).

Caso o empregado se manifeste, mesmo que comunicando sua intenção de não voltar, não irá configurar a justa causa, portanto não pode haver qualquer manifestação por parte do empregado. Para que seja caracterizado, a obrigação de prestar serviço deve estar vigente, deve haver ausência ininterrupta do empregado e não ter a manifestação da vontade (GIGLIO, 2000).

Ato lesivo da honra ou da boa fama praticado no serviço contra qualquer pessoa, ou ofensas físicas, nas mesmas condições, salvo em caso de legítima defesa, própria ou de outrem, o tipo jurídico, nas palavras de Garcia (2017, p. 394) "refere-se à conduta do empregado, em serviço, que viola os direitos de personalidade, no caso, relacionados à imagem e à moral, de qualquer pessoa".

Ato lesivo da honra ou da boa fama ou ofensas físicas praticadas contra o empregador e superiores hierárquicos, salvo em caso de legítima defesa, própria ou de outrem, prevê nesta alínea o mesmo disposto na alínea anterior, mas neste caso a conduta deve ser praticada contra superior hierárquico.

São considerados jogos de azar aqueles em que o resultado dependa exclusivamente da sorte. Para que se configure como justa causa, deve haver uma prática habitual dos jogos, repercutindo no ambiente laboral (GARCIA, 2017).

Perda da habilitação ou dos requisitos estabelecidos em lei para o exercício da profissão, em decorrência de conduta dolosa do empregado, esta hipótese ocorrerá quando o empregado perder a capacidade para algum fim, caberá a justa causa se o empregado perder a habilitação ou os requisitos estabelecidos em lei para exercer a profissão (CASSAR, 2018).

Martins (2018, p. 237) exemplifica o dispositivo "pode ser o caso de a pessoa perder a condição do exercício da profissão pelo fato de que o Conselho ou Ordem da profissão cassou o exercício da profissão do empregado em razão de conduta dolosa por ele cometida". 


\section{OS OBSTÁCULOS PARA MANUTENÇÃO DA RESCISÃO DO CONTRATO INDIVIDUAL DE TRABALHO POR JUSTA CAUSA}

Por se tratar da penalidade mais gravosa aplicada ao trabalhador, é necessário que sejam observadas algumas exigências para que a mesma seja configurada. Visto que, se não aplicada de forma correta, a justa causa poderá ser revertida posteriormente na justiça do trabalho.

Existem alguns requisitos na aplicação das penalidades que devem ser observados à luz do caso concreto. Os requisitos objetivos são vários. Iniciamos pelo requisito de tipicidade da conduta, conforme explanado por Martins (2020, p. 593) "a justa causa seja tipificada em lei, ou seja, não haverá justa causa se não houver determinação da lei. É a aplicação da regra do Direito Penal de que nullum crimen nulla poena sine lege (ART. 5, XXXIX, DA CONSTITUIÇÃO)".

Outro requisito objetivo é a relação com a natureza da matéria, devendo restringir a conduta do obreiro exclusivamente as obrigações contratuais, não estendendo às condutas pessoais. Nesse sentido explana Delgado (2017, p.787) "não há possibilidade de as prerrogativas do poder disciplinar estenderem-se ao universo de condutas estritamente pessoais, familiares, sociais e políticas do trabalhador".

O requisito da gravidade do ato praticado, deve ocorrer de modo que abale a relação de trabalho, devendo a gravidade da infração atuar como dosagem na aplicação da pena (MARTINS, 2020).

Já os requisitos subjetivos têm relação com a autoria da infração, dolo ou culpa em relação ao fato ocorrido. Deverá ser verificado se o empregado agiu com culpa ou com dolo e se ele realmente teve a intenção de praticar o ato (GARCIA, 2017).

Temos também os requisitos circunstanciais, são aqueles que dizem respeito a atuação do empregador diante da falta cometida. Dentre eles temos o nexo de causa, a proporcionalidade, a imediaticidade da punição, a ausência do perdão tácito, a singularidade da punição, a ausência de discriminação, o caráter pedagógico, entre outros elencados pelos doutrinadores (DELGADO, 2017).

A singularidade da punição, diz respeito a proibição de dupla punição, ou seja, a aplicação de duas penas referente ao mesmo ato faltoso. No direito do trabalho é vedada uma segunda punição pelo mesmo fato, para que não haja uma instabilidade 
no ambiente laboral, de angústias e incertezas, sendo revogada a próxima, se houver (GIGLIO, 2000).

Importante destacar que deve haver uma proporcionalidade na aplicação da pena, ponderando o ato que foi praticado com a pena que será aplicada. Caso seja entendimento do judiciário, se houver uma desproporcionalidade na aplicação, poderá a mesma ser revertida, conforme o entendimento firmado:

\begin{abstract}
JUSTA CAUSA. DESÍDIA. GRAVIDADE. GRADAÇÃO DE PENALIDADES. MANUTENÇÃO. Em se tratando de desídia, a gravidade da conduta, via de regra, está atrelada à repetição de atos faltosos que demonstrem a negligência do trabalhador com os deveres inerentes e acessórios ao contrato. Nesse contexto, ganha especial destaque a observância, pelo empregador, da gradação de penalidades, como forma de propiciar ao obreiro a adequação do seu comportamento às expectativas ordinárias da empresa, mantendo-se, assim, incólume o vínculo de emprego. A justa causa deverá ser, dentro de lógica fundada no princípio da proporcionalidade, a última "ratio" do empregador, aplicável quando tenham se mostrado inexitosas as tentativas precedentes de ajustar a conduta do trabalhador. Quando, contudo, da primeira ausência obreira comprovada, a empresa a tem por injustificada, resulta demasiada a aplicação respectiva da dispensa motivada na penalidade máxima que, assim, foi revertida em primeiro grau. Decisão mantida. (BRASIL, Tribunal Regional do Trabalho. 12a Região. Recurso Ordinário. Processo n. 0000881-47.2019.5.12.0035, 5 a Câmara. Relator: Ligia Maria Teixeira Gouvêa. Data de Julgamento: 22/07/2020. Data da Publicação: 22/07/2020).
\end{abstract}

A desídia tem relação com a negligência do trabalhador, ou seja, quando o mesmo passa a agir com desleixo no cumprimento de suas obrigações. Portanto para seja configurada a justa causa, deve haver uma repetição do ato faltoso, devendo o empregador graduar as penalidades, no intuito de tentar ajustar a conduta do mesmo para então poder aplicá-la, somente nos casos em que não houver outra alternativa. Bem como dispor de um acervo probatório consistente, que demostre os atos praticados pela parte, dificultando assim que incorra na reversão.

Nas palavras de Martinez (2014, p. 818):

A desídia é um comportamento caracterizado pela incúria do agente. Em decorrência de fatores subjetivamente culposos, ela se caracteriza a partir da reiteração de atos descurados, que são apenados, em regra, depois de uma atuação pedagogicamente gradativa do empregador. Encontram- se na desídia, portanto, dois importantes componentes: um de natureza objetiva, presente no descumprimento do dever de diligência, e outro de natureza subjetiva, constante da atitude desdenhosa e descomprometida com os resultados. 
Conforme elucida Sergio Pinto Martins (2018, p. 38) a respeito da proporcionalidade entre o ato faltoso e a punição:

[...] uma falta sem grande importância deveria ser punida com advertência verbal, outra falta praticada pelo mesmo empregado seria punida com advertência por escrito. Numa próxima, seria suspenso. Se o empregado não atende aos aspectos pedagógicos das penas que lhe foram aplicadas e continua recalcitrante, na última falta deve ser punido com a dispensa motivada. É claro que necessariamente o empregador não deve observar essa ordem, principalmente quando o ato cometido pelo empregado é tão grave, ocasião em que deve ser dispensado imediato. Entretanto, deve haver razoabilidade e bom-senso do empregador na aplicação das penalidades. $\mathrm{O}$ empregador poderia, ainda, aplicar pena mais branda do que realmente seria a devida, correndo o risco de gerar indisciplina no local de trabalho.

Podemos entender que ao aplicar a punição deve ficar evidente que o empregador tem o intuito de dar novas chances ao empregado, tendo a penalidade caráter educativo, para tentar adequar o funcionário a forma de trabalho da empresa, deixando a justa causa como última alternativa, quando não houver outras possibilidades.

Com relação a desproporcionalidade temos a fala do doutrinador Wagner Giglio (2000, p. 16):

\begin{abstract}
A desproporcionalidade entre $o$ ato faltoso e sua punição pode assumir dois aspectos: rigor excessivo da pena e benevolência da punição. No primeiro caso, excedendo-se na pena aplicada, exorbita o empregador de seus poderes de comando e responde pelas consequências de sua reação desmedida, sujeitando-se à cassação judicial do seu ato e ao ressarcimento dos prejuízos causados ao empregado: devolução, dos descontos salarias, se se tratar de suspensão, pagamento do acréscimo de $40 \%$ sobre os depósitos do FGTS, e ainda aviso prévio, férias e gratificação natalina proporcionais. No segundo, corre o empregador o risco de ensejar a indisciplina entre seus empregados, por ineficácia da punição, branda demais para coibir os excessos faltosos. $E$ isso porque não lhe é permitido renovar a punição, pela mesma falta. Seu direito de punir se esgota com a aplicação da penalidade escolhida.
\end{abstract}

O ônus probatório é incumbido à parte patronal, portanto, para que seja configurado, a empresa precisa provar que a conduta de fato ocorreu, bem como a intenção do obreiro em causar o resultado. Caso seja questionada em juízo, as provas devem ser evidentes, para não incorrer em reversão.

REVERSÃO DA JUSTA CAUSA. AUSÊNCIA DE PROVA ROBUSTA DOS FATOS QUE A FUNDAMENTAM. Diante dos reflexos nefastos que 
acarretam ao trabalhador, os fatos que fundamentam a dispensa por justa causa devem ser suficientemente graves e robustamente comprovados nos autos. Não tendo a empregadora produzido prova de tais fatos, deve ser revertida a justa causa aplicada pela empregadora. (BRASIL, Tribunal Regional do Trabalho. 12a Região. Recurso Ordinário n. 000053419.2019.5.12.0001. 5a Câmara. Relator: Narbal Antônio de Mendonça Fileti. Data de julgamento: 23/07/2020. Data de Publicação: 23/07/2020). (BRASIL, 2020)

No julgamento em contento fica evidente a necessidade de prova robusta para comprovar os fatos. O relator concluiu, pelo conjunto probatório, que houve a compra que estava sendo questionada e o valor registrado pela operadora de caixa foi menor do que os itens comprovadamente passados, mas que não houve comprovação da integridade do sistema de registro das mercadorias e também não foi comprovada a má-fé na conduta da autora em obter vantagens para si. Por esses fatos o mesmo havia optado em reverter a rescisão, mas que optou por negar provimento pelos fundamentos expostos a seguir:

[...] Compulsando os autos, verifico ser incontroverso que os produtos selecionados pela autora para compra realizada no dia 21 maio 2019, totalizavam quase $R \$ 100,00$, incluindo bebidas alcoólicas com preços unitários de dezenas de reais. Resta incontroverso, ainda, que a autora pagou apenas o valor aproximado e correspondente a $40 \%$ do valor dos produtos que estava adquirindo. Em depoimento, a autora disse não achar estranho $o$ valor tão reduzido, tendo em vista o desconto a que tinha direito (resposta 3 ). Logo, ao contrário da tese exposta na inicial, ela estava totalmente ciente quanto ao valor da compra, seu valor reduzido quando comparado com os produtos que estava adquirindo. A prova emprestada às fls. 147/9 (depoimentos das testemunhas na RTOrd 0000685-07.2019.5.12.0026) comprova que o desconto referido pela autora era de apenas "', $7 \%$ percentual este que não permite a alegação de que o desconto poderia ter induzido a erro a autora, pois muito distante da diferença entre o valor pago e aquele que efetivamente correspondia aos produtos selecionados para compra, cuja diferença corresponderia a um desconto de aproximadamente $60 \%$. Portanto, pouco importa a autora buscar comprovar que poderia haver problema no sinal sonoro do caixa e que os produtos podem não ter sido registrados, para, daí, se cogitar que tanto ela quanto a colega operadora de caixa tiveram um momento de desatenção coletiva, deixando ambas de perceber o valor de menos de $R \$ 40,00$ para produtos que notoriamente excederiam isso, uma vez que incluíam uma dúzia de cervejas, duas garrafas de conhaque, uma garrafa de vinho branco, carne e guloseimas. Saliento que o valor efetivamente pago cobre tão somente o valor das cervejas e de uma das garrafas de conhaque, mas a autora busca fazer crer que não notou a diferença de preço. Por certo, o Magistrado deve conduzir o julgamento com base nas provas produzidas nos autos. Por outro lado, não se pode esquecer que a presunção é de fundamental importância para elucidar inúmeras questões, inclusive fraudes e manobras ilícitas. Com base nos indícios, o Magistrado, através de um raciocínio lógico-jurídico, conclui (BRASIL, Tribunal Regional do Trabalho. $12^{\mathrm{a}}$ Região. Recurso Ordinário n. 000053419.2019.5.12.0001. $5^{a}$ Câmara. Relator: Narbal Antônio de Mendonça Fileti. 
Data de julgamento: 23/07/2020. Data de Publicação: 23/07/2020). (BRASIL, 2020).

Conforme analisado no entendimento acima, o recurso pleiteado em busca da reversão da justa causa foi negado pela turma recursal, entretanto mostra-se claro a necessidade da devida comprovação dos fatos, bem como comprovar a intenção do autor em praticar o ato, visto que no primeiro momento o relator optou em reverter a rescisão.

\section{CONCLUSÃO}

Frente à dificuldade e insegurança enfrentada pelos empregadores na aplicação da justa causa, realizou-se uma abordagem com base na doutrina e na jurisprudência acerca da modalidade rescisória, analisando seus principais aspectos e características para que seja configurada.

O desenvolvimento do presente artigo possibilitou uma análise de como deve ser aplicada as demissões por justa causa, para que a mesma seja configurada. Bem como quais os requisitos precisam estar presentes para que não seja revertida se questionada em juízo.

A justa causa é uma forma de rescisão do contrato individual de trabalho, ela pode ser aplicada nos casos em que houver uma ruptura contratual, devendo tal ato, praticado pelo empregado, estar de acordo com as hipóteses previstas em lei para que seja válido.

O poder empregatício confere poderes ao empregador para que ele possa aplicar sanções ao empregado que agir em desacordo do que for pactuado no contrato de trabalho. Sendo a justa causa a punição mais grave do contrato de trabalho.

Por se tratar da penalidade mais gravosa é necessário que estejam presentes requisitos objetivos e subjetivos para que seja configurada. Deve haver uma previsão legal do ato praticado, bem como ter relação com a natureza da matéria, ser comprovada sua gravidade e a relação do empregado com a autoria da infração. A atualidade tem relação com a aplicação ser feita de imediato, logo após o conhecimento do fato. 
Para que o empregador não corra o risco de a dispensa motivada ser revertida, ele precisa deixar evidente o fato de que pela gravidade não havia outra alternativa senão aplicar a justa causa, ou mesmo mostrar que tentou através de penalidades educativas enquadrar o funcionário a dinâmica de trabalho da empresa, mas que não logrou êxito, restando assim aplicar a justa causa.

Considerando todas as análises feitas no presente artigo, podemos concluir que a empresa que for aplicar a demissão por justa causa deverá certificar-se de estarem presentes todos os requisitos, ou seja, não se pautar apenas na letra da lei, caso não estejam presentes todos os requisitos poderá ensejar em reversão da justa causa, conforme examinado nas jurisprudências, nos julgados, fazendo com que a rescisão do contrato de trabalho seja mais gravosa para a empresa.

\section{REFERÊNCIAS}

BARROS, Alice Monteiro de. Curso de direito do trabalho. 7. ed. São Paulo: LTr, 2011.

BRASIL. Constituição Federal de 1988, de 05 de outubro de 1988. Constituição da República Federativa do Brasil. Diário Oficial da União, Brasília, DF, n 191-A de 05 de outubro de 1988.

BRASIL. Decreto-Lei 5.452, de $1^{\circ}$ de maio de 1943. Consolidação das Leis do Trabalho. Brasília, DF, 01 maio 1943. Disponível em http://www.planalto.gov.br/ccivil_03/decreto-lei/del5452.htm. Acesso em: 24 mar. 2020.

BRASIL. Tribunal Regional do Trabalho. 12a Região. Recurso Ordinário $\mathbf{n}$. 0000534-19.2019.5.12.0001. 5a Câmara. Recorrente: Karla Roberta Lino de Araujo. Recorrido: SDB Comércio de Alimentos LTDA. Relator: Narbal Antônio de Mendonça Fileti. Data de julgamento: 23/07/2020. Pesquisa de Jurisprudência TST. Data de publicação: 23 jul. 2020. Disponível em: http://www.trt12.jus.br/. Acesso em: 28 ago. 2020.

BRASIL, Tribunal Regional do Trabalho. Recurso Ordinário. 12a Região. Processo n. 0000881-47.2019.5.12.0035, 5 a Câmara. Recorrente: Embracon Asseio e Conservacao LTDA. Recorrido: Michele Regina Cardoso. Relator: Ligia Maria Teixeira Gouvêa. Data de Julgamento: 22/07/2020. Pesquisa de Jurisprudência TST. Data de publicação: 22 jul. 2020. Disponível em: http://www.trt12.jus.br/. Acesso em: 28 ago. 2020.

CASSAR, Vólia Bomfim. Direito do Trabalho. 14. ed. rev., atual. e ampl. Rio de Janeiro: Forense; São Paulo: MÉTODO, 2017. 
DELGADO, Mauricio Godinho. Curso de direito do trabalho. 16. ed. rev. e ampl.. São Paulo: LTr, 2017.

GARCIA, Gustavo Filipe Barbosa. Curso de direito do trabalho. 11. ed. rev. atual. e ampl. Rio de Janeiro: Forense, 2017.

GIGLIO, Wagner D. Justa causa. 7. ed. rev. e atual. São Paulo: Saraiva, 2000.

LEITE, Carlos Henrique Bezerra. Curso de direito do trabalho. 8. ed. São Paulo: Saraiva, 2017.

MARTINEZ, Luciano. Curso de direito do trabalho: relações individuais, sindicais e coletivas do trabalho. 7. ed. São Paulo: Saraiva, 2016.

MARTINS, Sergio Pinto. Direito do trabalho. 25. ed. São Paulo: Atlas, 2009.

MARTINS, Sergio Pinto. Direito do trabalho. 36. ed. São Paulo: Saraiva Educação, 2020.

MARTINS, Sergio Pinto. Manual da justa causa. 7. ed. São Paulo: Saraiva Educação, 2018.

NASCIMENTO, Amauri Mascaro; NASCIMENTO, Sônia Mascaro. Curso de direito do trabalho: história e teoria geral do direito trabalho: relações individuais e coletivas do trabalho. 29. ed. São Paulo: Saraiva, 2014.

Artigo recebido em: 28/09/2020

Artigo aceito em: 18/11/2020

Artigo publicado em: 13/10/2021 